\title{
Use of prescribed drugs among primiparous women: an II-year population-based study in Denmark
}

This article was published in the following Dove Press journal:

Clinical Epidemiology

30 April 20II

Number of times this article has been viewed

\author{
Anne-Mette Bay Bjørn' \\ Mette Nørgaard' \\ Heidi Holmager Hundborg' \\ Ellen Aagaard Nohr ${ }^{2}$ \\ Vera Ehrenstein' \\ 'Department of Clinical Epidemiology, \\ Aarhus University Hospital, \\ ${ }^{2}$ Department of Epidemiology, \\ Institute of Public Health, University \\ of Aarhus, Denmark
}

\begin{abstract}
Purpose: To describe patterns of prescribed drug use over time among primiparous women in Denmark.

Methods: Through the Danish Medical Birth Registry, we identified all primiparous women giving live birth or stillbirth at $\geq 22$ gestational weeks in northern Denmark, from 1999 to 2009 . From the Aarhus University Prescription Database we obtained information on the women's prescriptions for reimbursed drugs filled from 30 days before conception until delivery.

Results: Among 85,710 primiparous women, 47,982 (56.0\%) redeemed at least one prescription from 30 days before conception until delivery. Women aged 35 years and older had the highest overall prevalence of prescription drug use (61.1\%). Age-standardized prevalence of drug use was $54.7 \%$ in 1999 and $61.2 \%$ in 2009 , prevalence ratio (PR) of 1.13 (95\% confidence interval $1.10 ; 1.16)$, adjusted for age and smoking.

Conclusion: Over the 11-year period from 1999 to 2009, we found a modest increase in overall use of drugs by primiparous women in Denmark. This increase was not, however, explained by an increasing proportion of older first-time mothers. We noted changes in patterns of use of anti-infective drugs and antidepressants.
\end{abstract}

Keywords: drug utilization, epidemiology, pregnancy

\section{Introduction}

Reported prevalence of drug use during pregnancy in Western countries ranges from $44 \%$ to $99 \%$, and many pregnant women use several different drugs. ${ }^{1-7}$ Because pregnant women are typically excluded from randomized studies of drugs, evidence about drug utilization and safety in pregnant women comes primarily from surveillance. ${ }^{8,9}$

Despite lack of data on safety, drug therapy during pregnancy is sometimes required to treat maternal conditions. ${ }^{10}$ Women in developed countries are delaying childbearing into later reproductive years: ${ }^{11}$ in Denmark, the prevalence of first-time mothers older than 30 years has increased from $29 \%$ in 1997 to $41 \%$ in $2007 .{ }^{12}$ Temporal changes in demographic, social, or clinical characteristics of pregnant women as well as modifications in treatment guidelines may affect patterns of drug utilization in pregnancy. ${ }^{10,13}$

Previous studies have mainly reported period prevalence of drug use among pregnant women, and have examined use according to trimester of pregnancy. ${ }^{1-7}$ Little data exist on temporal changes in drug use during pregnancy. ${ }^{10,14}$ In this population-based study, we examined changes in patterns of prescribed drug use from 1999 to 2009 among Danish primiparous women.
Correspondence: Anne-Mette Bay Bjørn Department of Clinical Epidemiology, Olof Palmes Allé 43-45, 8200 Aarhus N, Denmark

Tel +4589424800

Fax +4589424801

Email abb@dce.au.dk 


\section{Methods}

\section{Study population}

In the Danish Medical Birth Registry, we identified all primiparous women (ie, women delivering their first live- or stillborn child at $\geq 22$ weeks' gestation) ${ }^{15}$ from 1 January 1999 to 31 December 2009 in the Central and the North Denmark Regions, which together comprise about 33\% of the total Danish population (1.8 million people). The Medical Birth Registry has recorded all births in Denmark since 1973 and contains data on characteristics of the mother (including age, residence, parity, and self-reported smoking status) and the newborn (including vital status at birth, sex, gestational age, and birth weight). ${ }^{16}$ The information on gestational age is based on ultrasound and is recorded in full completed weeks (through 1996) and in fractional weeks (based on days) thereafter. ${ }^{17}$ We calculated the conception date as birth date minus gestational age in days plus 14 days.

\section{Identification of prescribed drugs}

We obtained information on drug use in pregnancy using the Aarhus University Prescription Database, which tracks prescriptions for reimbursed drugs redeemed at the regions' outpatient pharmacies. ${ }^{18}$ The pharmacies use electronic accounting systems to secure reimbursement from the National Health Service. Denmark's tax-supported health care system partially refunds the costs of most prescribed drugs. ${ }^{19}$ To secure full prescription records for each pregnancy in the study population, we restricted our study to women who were residents of the two regions from 30 days before conception until delivery and who were therefore assumed to have redeemed their prescriptions in the regions' outpatient pharmacies.

We defined drug use as a record of at least one prescription dispensation recorded in the Aarhus University Prescription Database from 30 days before conception until delivery. For all prescriptions, we noted the woman's personal identifier, date of reimbursement, and type of medication, coded using the Anatomical Therapeutic Chemical (ATC) classification. The Aarhus University Prescription Database does not track in-hospital medicinal treatment. Nonreimbursed drugs (over-the-counter [OTC] preparations, prescription sedatives, hypnotics, or oral contraceptives) are not recorded unless they are approved for reimbursement, eg, to treat a chronic condition. ${ }^{18}$

\section{Data linkage}

Data were linked using the unique 10-digit personal identifier ("CPR number"), assigned to all Danish residents at birth by the Civil Registration System since $1968 .{ }^{20}$ The CPR number, which encodes date of birth and sex, is used in all public records. Maternal CPR number is a variable on the newborn's Medical Birth Registry entry, enabling unambiguous linkage to the maternal prescription record. Furthermore, the Civil Registration System contains a variable encoding residence.

\section{Statistical analyses}

We computed prevalence of drug use among primiparous women according to maternal age at delivery $(<25$ years, 25-29 years, 30-34 years, and $\geq 35$ years), smoking during pregnancy (yes/no), and categories corresponding to the major anatomical ATC groups. ${ }^{21}$ We further analyzed six major anatomical ATC groups with prevalence of use in pregnancy exceeding $4 \%$. These groups, listed in the order of decreasing prevalence of use, were: anti-infective drugs for systemic use (ATC group J), gynecological drugs (ATC group G), dermatological drugs (ATC group D), drugs for respiratory diseases (ATC group R), drugs for alimentary tract and metabolism (ATC group A), and neurological drugs (ATC group N). In 1998, clinical guidelines were introduced in Denmark for treatment of asymptomatic urinary tract infections in pregnancy. ${ }^{22,23}$ For anti-infective drugs, we therefore specifically examined prevalence of drug use indicated for urinary tract infections (UTIs) (sulfamethizole (J01EB02), pivmecillinam (J01CA08), and nitrofurantoin (J01XE01)), while examining use of penicillin (phenoxymethylpenicillin (J01CE02), pivampicillin (J01CA02), and amoxicillin (J01CA04)) for comparison. After observing an increasing trend in use of neurological drugs throughout the study period, we did a post-hoc analysis to examine change over time in prevalence of drug use in specific subgroups: antidepressants (N06A), anti-epileptics (N03), and opioids (N02A).

We computed age-standardized prevalence of drug use in each calendar year (1999-2009), with age distribution in year 1999 as the standard. Further, we estimated age- and smoking-adjusted prevalence ratios (PRs) for drug use with corresponding 95\% confidence intervals (CIs), using 1999 as the referent year. Furthermore, we tested for presence of a trend across years using the Chi-square test for trend.

We examined patterns of drug use over time within four gestational periods: immediate pre-conception (1-30 days before estimated conception), first trimester (gestational week 1-12), second trimester (gestational week 13-28), and third trimester (gestational week 29 to delivery). We compared pre-conception and trimester-specific 
Table I Characteristics of primiparous women in Northern Denmark 1999-2009

\begin{tabular}{|c|c|c|}
\hline & $\begin{array}{l}\text { All primiparous } \\
\text { women } \\
(n=85,7 \mid 0)\end{array}$ & $\begin{array}{l}\text { Primiparous women } \\
\text { who redeemed at least } \\
\text { one prescription during } \\
\text { pregnancy } \\
(n=47,982)\end{array}$ \\
\hline \multicolumn{3}{|c|}{ Age at delivery, years } \\
\hline$<25$ & $18,170(2 \mid .2)$ & $10,637(22.2)$ \\
\hline $25-29$ & $39,221(45.8)$ & $20,824(43.4)$ \\
\hline $30-34$ & $21,540(25.1)$ & $12,382(25.8)$ \\
\hline$\geq 35$ & 6779 (7.9) & $4139(8.6)$ \\
\hline $\begin{array}{l}\text { Smoking during } \\
\text { pregnancy }^{\mathrm{a}}\end{array}$ & I5,046 (I7.6) & $9014(18.8)$ \\
\hline Single births & 83,405 (97.3) & $46,348(96.6)$ \\
\hline Twin births & $2256(2.6)$ & 1593 (3.3) \\
\hline Triplet births & $49(0.1)$ & $4 I(0.1)$ \\
\hline $\begin{array}{l}\text { Low birth weight } \\
(<2500 \mathrm{~g})\end{array}$ & $3975(4.8)^{c}$ & $2309(5.0)^{c}$ \\
\hline $\begin{array}{l}\text { Preterm birth } \\
\text { (<37 weeks) }\end{array}$ & $5550(6.7)^{c}$ & $3217(6.9)^{c}$ \\
\hline $\begin{array}{l}\text { Stillbirth } \\
\text { ( } \geq 22 \text { weeks) }\end{array}$ & $362(0.4)^{c}$ & $221(0.5)^{c}$ \\
\hline
\end{tabular}

Notes: ${ }^{\circledR} \mid 826$ missing values (2.1\%); ${ }^{b} 494$ missing values (0.6\%); 'Singleton pregnancies only.

prevalence of drug use in 1999-2000 (the first two years of observation) with that in 2008-2009 (the last two years of observation). Using years 1999-2000 as the reference, we estimated gestational-period specific prevalence ratios for drug use, adjusted for age at delivery and smoking in pregnancy.
All analyses were performed using Stata software 10.0 (College Station, TX). The study was approved by the Danish Data Protection Agency (journal number: 2003-41-3103).

\section{Results}

During the study period, we identified 85,710 primiparous women, delivering 88,003 live- or stillborn children. Mean age at delivery was 28 years (range $13-52$ years); the proportion of first-time mothers aged 30 years and older increased from $29.0 \%$ in 1999 to $35.8 \%$ in 2009 . Compared with all primiparous women, those with prescription drug use were more likely to be smokers, to have multiple births, and to be older. Prevalence of preterm birth and low birth weight differed slightly among groups (Table 1 ).

Overall, 47,982 (56.0\%) of primiparous women redeemed at least one prescription for a reimbursed drug from 30 days before conception until delivery. Women who redeemed prescriptions, redeemed, on average, 3.2 prescriptions $(2.3 \%$ of these redeemed $>10$ prescriptions). Women who used anti-infective drugs redeemed on average 1.6 prescriptions (lowest prescription rate per woman), whereas women who used neurological drugs on average redeemed 4.0 prescriptions (highest prescription rate per woman).

The age-standardized prevalence of drug use increased from $54.7 \%$ in 1999 to $61.2 \%$ in 2009 , PR 1.13 (95\% confidence intervals $[\mathrm{CI}]: 1.10 ; 1.16)$; the prevalence decreased slightly in the first two years of observation.The overall prevalence of drug use was $58.5 \%$ among women younger

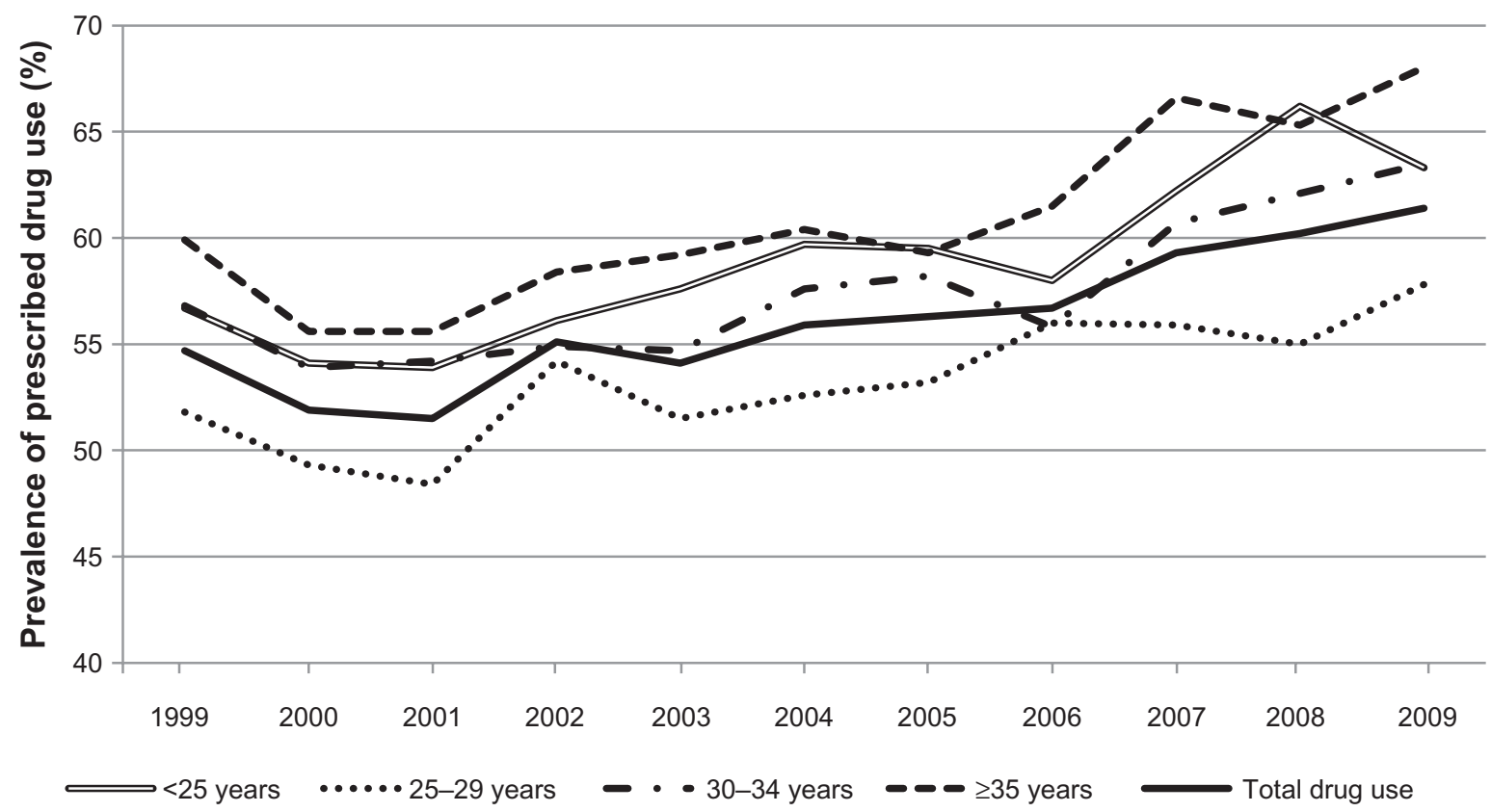

Figure I Prevalence of prescribed drug use according to age among primiparous women. Northern Denmark 1999-2009. 


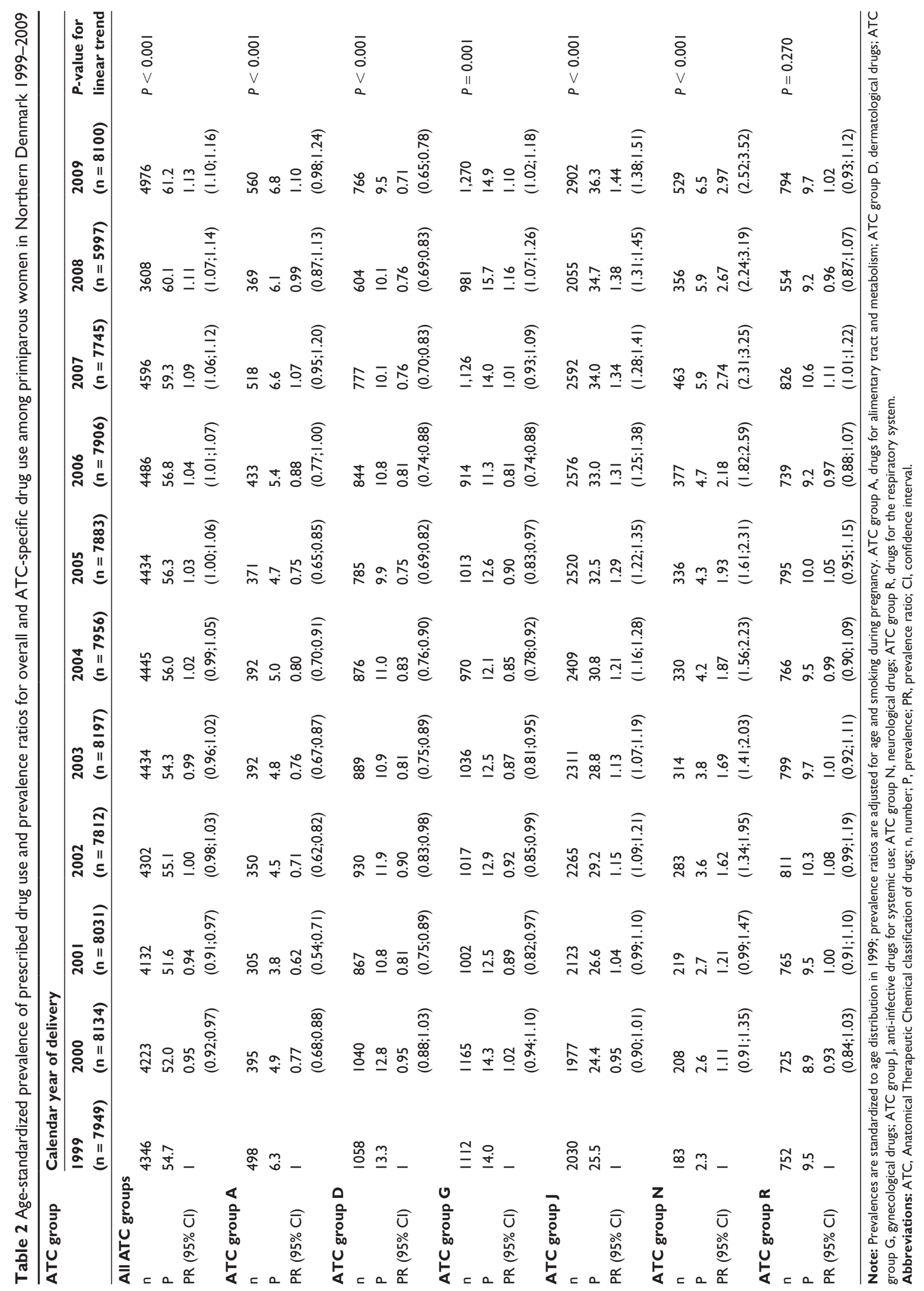


than 25 years, $53.1 \%$ among women between 25 and 29 years, $57.5 \%$ among women aged $30-34$ years, and $61.1 \%$ among women aged 35 years and older. Throughout the study period, women aged 25-29 years had a lower prevalence of drug use than women in other age groups (Figure 1). Drug use over time in each age group was tested for trend $(P<0.001$ for linear trend in all age groups).

Table 2 shows prevalence of drug use stratified by calendar year and ATC group and PRs of drug use adjusted for age and smoking. Anti-infective drugs were the most prevalent drugs used the by the primiparous mothers as measured by one or more dispensed prescriptions. The age-standardized prevalence of use of anti-infective drugs increased from $25.5 \%$ in 1999 to $36.3 \%$ in 2009, PR 1.44 (95\% CI: 1.38; 1.51). Women younger than 25 years had a higher prevalence of anti-infective drug use $(37.3 \%)$ compared with women in all other age groups: $28.1 \%$ of women between 25 and 29 years; $28.3 \%$ of women aged $30-34$; and $27.8 \%$ of women aged 35 years and older. There were 14,469 (16.9\%) women redeeming one or more prescriptions for UTI antibiotic drugs and 11,761 (13.7\%) women redeeming one or more prescriptions for penicillin. The prevalence of UTI-specific drug use more than doubled (10.9\% in $1999 ; 22.9 \%$ in 2009 , PR 2.15 [95\% CI: $1.99 ; 2.31])$ and the increasing prevalence was observed in all age groups (data not shown). We also observed an increase over time in the prevalence of penicillin use (13.3\% in 1999 ; $14.1 \%$ in 2009, PR 1.10 (95\% CI: 1.02; 1.19)).

The age-standardized prevalence of neurological drug use increased nearly three-fold $(2.3 \%$ in $1999 ; 6.5 \%$ in
2009, PR 2.97 [95\% CI: 2.52; 3.52]) (Table 2). At any time during pregnancy, $1872(2.2 \%)$ women used antidepressants, $582(0.7 \%)$ used opioids, and 451 (0.5\%) used anti-epileptics. Prevalence of antidepressant use increased nearly six-fold (0.8\% in 1999; 4.1\% in 2009, PR 5.95 [95\% CI: 4.51; 7.85]).

Prevalences of gestational-period specific drug use in 1999-2000 and 2008-2009 are shown in Figure 2. Over time, prevalence of immediate pre-conception and trimester-specific use of anti-infective drugs increased. Prevalence of trimesterspecific use of neurological drugs also changed over time. For example, first-trimester use increased more that three-fold from $1.4 \%$ in $1999-2000$ to $4.1 \%$ in $2008-2009$, PR 3.19 (95\% CI: $2.73 ; 3.74)$; second trimester use increased more that fourfold from $0.8 \%$ in 1999 to $3.4 \%$ in 2009 , PR 4.30 (95\% CI: $3.54 ; 5.22)$; and third trimester use increased from $0.7 \%$ in 1999 to $2.3 \%$ in 2009 , PR 3.54 (95\% CI: $2.85 ; 4.40)$. Prevalence of immediate pre-conception use of gynecological drugs more than doubled from 1999-2000 to 2008-2009 (3.9\% in 1999-2000; 9.3\% in 2008-2009, PR 2.18 (95\% CI: 2.00; 2.39), whereas third-trimester use almost halved from $3.2 \%$ in $1999-2000$ to $1.8 \%$ in 2008-2009, PR 0.57 (95\% CI: 0.49; 0.66).

\section{Discussion}

Use of prescribed reimbursed drugs increased modestly (6.5\% in absolute terms) from 1999 to 2009 in this population of almost 86,000 primiparous women. From 2001 to 2005, the Danish Institute of Public Health reported a $24 \%$ increase of prescribed drug use measured in defined daily doses (DDDs) among the general Danish population. ${ }^{24}$ The

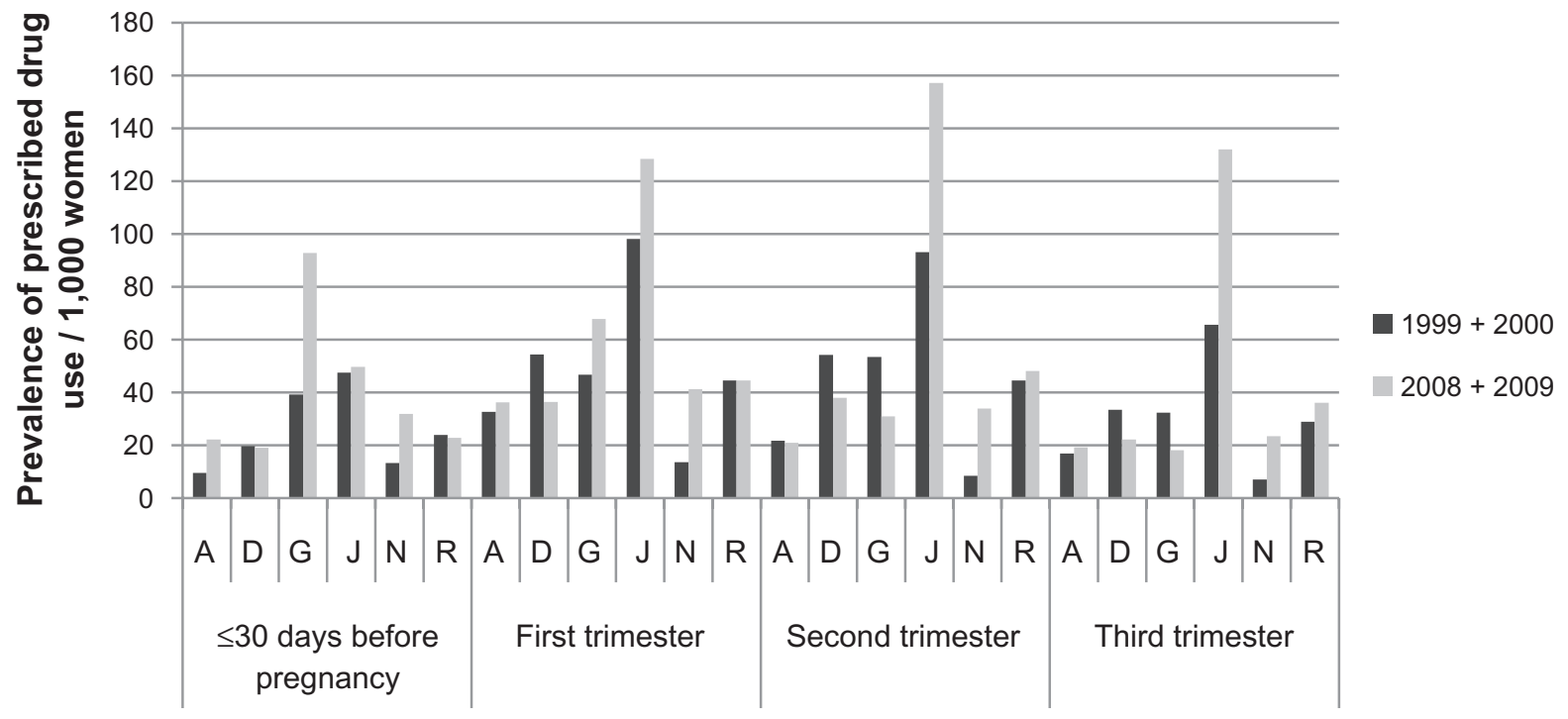

Figure 2 Prevalence (per 1000 women) of immediate pre-conception and trimester-specific drug use among primiparous women for the most commonly prescribed ATC groups $^{\mathrm{a}}$ 1999-2000 and 2008-2009.

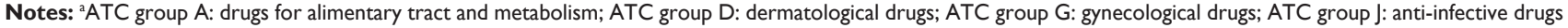
for systemic use; ATC group N: neurological drugs; and ATC group R: drugs for the respiratory system. 
observed modest increase in drug use among women giving first birth could thus be a reflection of this general population trend. The overall prevalence of drug use increased with age; however, increasing age of primiparous women did not explain the overall increase in prevalence of drug use over time. Anti-infective drugs were used with the highest prevalence as measured by one or more prescription dispensation. Prevalence of antidepressant use increased substantially over the observation period, but the absolute prevalence remained low.

Prevalence of drug use in pregnancy was on the same order of magnitude in other Nordic countries as in the present study. In Sweden (2007), the prevalence of drug use was 58\% among pregnant women; ${ }^{7}$ in 2004-2006, in Norway, prevalence of drug use during pregnancy was $57 \%$ at any time during trimester $1-3$ among first singleton pregnancies, ${ }^{3}$ while in Finland, the prevalence of use was $46 \%$ in $1999 .{ }^{5}$ Comparability of findings is expected as Nordic countries have similar health care and recordkeeping practices. ${ }^{25}$

Non-Nordic countries have reported higher prevalence of drug use during pregnancy. ${ }^{1,2,4}$ According to records from the French Health Insurance Service, 99\% of women in Southwest France receive prescribed drugs during pregnancy. ${ }^{4}$ In the United States, $82 \%$ of pregnant women used prescribed drugs, based on data collected from the Health Maintenance Organizations (HMO) in 1996-2000. ${ }^{1}$ Both in France and in the United States, the reported drug use includes certain OTC medications, such as iron, folic acid, and pregnancy vitamins. In particular, in the United States (in contrast to Denmark), pregnant women receive prescriptions for pregnancy vitamins in order to enable reimbursement, and therefore leading to a dispensation record. Thus, patterns of drug utilization during pregnancy can be expected to vary according to prescribing, reimbursement, and record-keeping practices, as well as socioeconomic differences. ${ }^{1-5}$

Drug utilization patterns varied by age and by type of drug. Our finding that women aged 35 years or older had a slightly higher prevalence of overall drug use than women in younger age groups is similar to findings in a recent Irish study including 61,252 women giving birth in Dublin from 2000 to $2007 .{ }^{26}$ Young age, however, has been associated with a higher use of antibiotics, as observed in a German study of about 41,000 observations based on insurance claims. This observation was confirmed in our study. The German researchers attributed higher use of antibiotics by younger pregnant women to higher rates of infections in this age group. ${ }^{27}$ Screening for bacteriuria as part of routine examination of pregnant women was introduced in Denmark in $1998,{ }^{22,23}$ probably partially explaining our observation of increased use of UTI-specific drugs among women giving first birth throughout the study period. In 2001, some drugs used in treatment of gynecological infections were re-coded from gynecological drugs to the anti-infective drugs for systemic use, ${ }^{28}$ which may account for some of the decrease seen for gynecological drugs and some of the increase seen for anti-infective drug use observed in our study. An increased prevalence of prescribed antidepressant drug use seen in this study was also reported in the United States. ${ }^{29,30}$ Exposure to antidepressants (selective serotonin reuptake inhibitors [SSRIs] in particular) in early pregnancy has been associated with an increased risk of adverse neonatal effects. ${ }^{14,31,32}$ That, together with our findings that use of neurological drugs increased in early pregnancy during our study period, may call for further attention.

It is important to acknowledge different strengths and weaknesses of our study when interpreting our results. Our large and well defined study population contained data from a uniform health care system with complete coverage and universal access. We used data from a system of automatic reimbursement and routine electronic record-keeping. This enabled us to avoid recall bias, and estimate drug utilization systematically. ${ }^{33}$

We focused on trends in use of broad groups of prescription drugs according to major anatomical ATC-groups in order to give the general descriptive picture of drug utilization patterns among primiparous women. We did not aim to specifically address utilization of known or potential teratogens. Reports that almost $20 \%$ of Canadian women ( study population $=18,575)^{34}$ and $10 \%$ of US women (study population $=152,531)^{1}$ used prescription drugs with potential or clear fetal risk during pregnancy call for further attention. However, the teratogenic potential of many drugs is unknown ${ }^{35}$ and deserves special investigation.

The Aarhus University Prescription Database lacks information on dispensation of OTC drugs, in-hospital treatment, or sales of nonreimbursed prescribed drugs. ${ }^{18}$ Therefore the overall prevalence of prescription drug use among women giving first birth is underestimated and caution about conclusions regarding the observed change of drug utilization patterns in specific ATC-groups,eg neurological drugs, need to be considered. Furthermore, because we used information on redeemed prescriptions, we had no data about the true drug intake, potentially leading to overestimation of the actual use of the purchased drugs. ${ }^{36}$ Although we examined the effect on utilization of maternal 
age and self-reported smoking, we had no data on other factors, such as social status and years of education, which could also explain some of the change in use. Further, we restricted the study population to primiparous women to maximally remove the effects of age from evaluating the trends of drug use.

\section{Authors' contributions}

$\mathrm{AB}, \mathrm{MN}, \mathrm{EAN}$, and VE have all substantially contributed to study conception, design, and interpretation of data. $\mathrm{AB}$ and VE drafted the article. $\mathrm{AB}$ and $\mathrm{HH}$ analyzed the data, and $\mathrm{HH}$ participated in dataset creation. All authors revised the paper critically and approved the final version.

\section{Acknowledgments}

This work was supported in part by grants from the Augustinus Foundation, the Foundation of Dagmar Marshalls, the Foundation of the Faculty of Health in Central Region of Denmark, the Foundation of Sophus Jacobsen and Astrid Jacobsen, and Aarhus University.

\section{Disclosure}

The authors report no conflicts of interest in this work.

\section{References}

1. Andrade SE, Gurwitz JH, Davis RL, Chan A, Finkelstein JA, Fortman K, et al. Prescription drug use in pregnancy. Am J Obstet Gynecol. 2004;191(2):398-407.

2. Bakker M, Jentink J, Vroom F, Van den Berg P, de Walle H, de Jong-Van den Berg L. Drug prescription patterns before, during and after pregnancy for chronic, occasional and pregnancy-related drugs in the Netherlands. BJOG. 2006;113(5):559-568.

3. Engeland A, Bramness JG, Daltveit AK, Rønning M, Skurtveit S, Furu K. Prescription drug use among fathers and mothers before and during pregnancy. A population-based cohort study of 106,000 pregnancies in Norway 2004-2006. Br J Clin Pharmacol. 2008;65(5):653-660.

4. Lacroix I, Damase-Michel C, Lapeyre-Mestre M, Montastruc JL. Prescription of drugs during pregnancy in France. Lancet. 2000; 356(9243):1735-1736.

5. Malm H, Martikainen J, Klaukka T, Neuvonen PJ. Prescription drugs during pregnancy and lactation-a Finnish register-based study. Eur $J$ Clin Pharmacol. 2003;59(2):127-133.

6. Olesen C, Steffensen FH, Nielsen GL, de Jong-van den Berg L, Olsen J, Sørensen HT. Drug use in first pregnancy and lactation: a population-based survey among Danish women. Eur J Clin Pharmacol. 1999;55(2):139-144.

7. Stephansson O, Granath F, Svensson T, Haglund B, Ekbom A, Kieler H. Drug use during pregnancy in Sweden - assessed by the Prescribed Drug Register and the Medical Birth Register. Clin Epidemiol. 2011;3: 43-50.

8. Ehrenstein V, Sørensen HT, Bakketeig LS, Pedersen L. Medical databases in studies of drug teratogenicity: methodological issues. Clin Epidemiol. 2010;2:37-43.

9. Koren G. Ethical framework for observational studies of medicinal drug exposure in pregnancy. Teratology. 2002;65(4):191-195.

10. Koren G, Pastuszak A, Ito S. Drugs in pregnancy. N Engl J Med. 1998; 338(16):1128-1137.
11. Usta I, Nassar A. Advanced maternal age. Part I: obstetric complications. Am Jour Perinatol. 2008;25:521-534.

12. The National Board of Health, online data. Available from: http:// www.sst.dk/Indberetning\%20og\%20statistik/Sundhedsdata/Foedsler_ fertilitetsbehandling_og_abort/foedsler4.aspx. Accessed December 1, 2009.

13. Kenyon AP. Effect of age on maternal and fetal outcomes. Br J Midwif. 2010;18(6):358-362.

14. Cooper WO, Willy ME, Pont SJ, Ray WA. Increasing use of antidepressants in pregnancy. Am J Obstet Gynecol. 2007;196(6):544.el-544.e5.

15. Wilcox AJ. Fertility and pregnancy: an epidemiologic perspective. Oxford, New York: Oxford University Press; 2010.

16. Kristensen J, Langhoff-Roos J, Skovgaard LT, Kristensen FB. Validation of the Danish birth registration. J Clin Epidemiol. 1996;49(8):893-897.

17. Ehrenstein V, Pedersen L, Holsteen V, Larsen H, Rothman KJ, Sørensen HT. Postterm delivery and risk for epilepsy in childhood. Pediatrics. 2007;119:e554-e561.

18. Ehrenstein V, Antonsen S, Pedersen L. Existing data sources for clinical epidemiology: Aarhus University Prescription Database. Clin Epidemiol. 2010;2:273-279.

19. Ministry of Health and Prevention. Report: Health Care in Denmark, 2008. Available from: http://www.sum.dk/Aktuelt/Publikationer/Publikationer/ UK_Healthcare_in_DK.aspx. Accessed October 1, 2009.

20. Pedersen C, Gotzsche H, Møller J, Mortensen PB. The Danish Civil Registration System. A cohort of eight million persons. Dan Med Bull. 2006;53:441-449.

21. Danish Medicine Agency. ATC-classification system. Available from: http://www.medicinpriser.dk/Default.aspx?id=65. Accessed January 1, 2011.

22. National Board of Health. Report: Svangreomsorg - retningslinier og redegørelse. Published Jul 1998. ISBN: 87-90365-86-0.

23. National Board of Health. Report: Anbefalinger for svangreomsorgen, 2009. ISBN: (electronic version): 978-87-7676-905-5. Available from: http://www.sst.dk/Sundhed\%20og\%20forebyggelse/Graviditet/Anbe falinger\%20om\%20svangreomsorg.aspx. Accessed October 1, 2010.

24. Ekholm O, Kjøller M, Davidsen M, et al. The national health interview surveys, 1987-2005. The National Institute of Public Health. Report, 2006. ISBN: 978-87-7899-112-6.

25. Furu K, Wettermark B, Andersen M, Martikainen JE, Almarsdottir AB, Sørensen HT. The Nordic Countries as a cohort for pharmacoepidemiological research. Basic Clin Pharmacol Toxicol. 2010;106(2):86-94.

26. Cleary BJ, Butt H, Strawbridge JD, Gallagher PJ, Fahey T, Murphy DJ. Medication use in early pregnancy-prevalence and determinants of use in a prospective cohort of women. Pharmacoepidemiol Drug Saf. 2010;19(4):408-417.

27. Amann U, Egen-Lappe V, Strunz-Lehner C, Hasford J. Antibiotics in pregnancy: analysis of potential risks and determinants in a large German statutory sickness fund population. Pharmacoepidemiol Drug Saf. 2006;15(5):327-337.

28. The Danish Medicines Agency: Alterations in ATC-coding, 1996-2009. Available from: http://www.laegemiddelstyrelsen.dk/db/filarkiv/5048/ Bilag\%201.pdf. Accessed November 1, 2010.

29. Wichman C, Fothergill A, Moore K, Lang T, Heise R Jr, Watson W. Recent trends in selective serotonin reuptake inhibitor use in pregnancy. J Clin Psychopharmacol. 2008;28:714-716.

30. Bennett H, Einarson A, Taddio A, Koren G, Einarson TR. Prevalence of depression during pregnancy: systematic review. Obstet Gynecol. 2004;103(6):698-706.

31. Kornum JB, Nielsen RB, Pedersen L, Mortensen PB, Nørgaard M. Use of selective serotonin-reuptake inhibitors during early pregnancy and risk of congenital malformations: updated analysis. Clin Epidemiol. 2010;2:29-36.

32. Pedersen LH, Henriksen TB, Vestergaard M, Olsen J, Bech BH. Selective serotonin reuptake inhibitors in pregnancy and congenital malformations: population based cohort study. BMJ. 2009;339:b3569. 
33. Mitchell A,Cottler L, Shapiro S. Effect of questionnaire design on recall of drug exposure in pregnancy. Am J Epidemiol. 1986;123:670-676.

34. Yang T, Walker MC, Krewski D, et al. Maternal characteristics associated with pregnancy exposure to FDA category C, D, and $\mathrm{X}$ drugs in a Canadian population. Pharmacoepidemol Drug Saf. 2008;17(3):270-277.
35. Mitchell A. Studies of drug-induced birth defects. In: Storm B, editor. Pharmacoepidemiology. 4th ed. West Sussex: John Wiley and Sons Ltd; 2005;501-514.

36. Schneeweiss S, Avorn J. A review of uses of health care utilization databases for epidemiologic research on therapeutics. JClin Epidemiol. 2005;58(4):323-337.

\section{Publish your work in this journal}

Clinical Epidemiology is an international, peer-reviewed, open access journal focusing on disease and drug epidemiology, identification of risk factors and screening procedures to develop optimal preventative initiatives and programs. Specific topics include: diagnosis, prognosis, treatment, screening, prevention, risk factor modification, systematic

Submit your manuscript here: http://www.dovepress.com/clinical-epidemiology-journal

\section{Dovepress}

reviews, risk \& safety of medical interventions, epidemiology \& biostatical methods, evaluation of guidelines, translational medicine, health policies \& economic evaluations. The manuscript management system is completely online and includes a very quick and fair peer-review system, which is all easy to use. 